\title{
Assessment of community pharmacy professionals' knowledge and counseling skills achievement towards headache management: a cross-sectional and simulated-client based mixed study
}

Adeladlew Kassie Netere ${ }^{1 *}$, Daniel Asfaw Erku' ${ }^{1}$ Ashenafi Kibret Sendekie ${ }^{1}$, Eyob Alemayehu Gebreyohannes ${ }^{1}$, Niguse Yigzaw Muluneh ${ }^{2}$ and Sewunet Admasu Belachew ${ }^{1}$

\begin{abstract}
Background: Headache is one of the most common disabling medical condition affecting over $40 \%$ of adults globally. Many patients with headache prefer to alleviate their symptom with a range of over-the-counter analgesics that are available in community medicine retail outlets (CMROs). However, data regarding how community pharmacists respond to headache presentation and their analgesic dispensing behaviors in Ethiopia is scarce. The present study aimed to assess the self-reported and actual practice of community pharmacists toward management of a headache in Gondar town, Ethiopia.

Methods: A dual-phase mixed-methods research design, including pseudo-client visits (between April 1 and 30, 2018) followed by a questionnaire-based cross-sectional study (between May 1 and 20, 2018) was conducted among CMROs in Gondar town, Ethiopia.

Results: Among the 60 pseudo-client visits, 95\% of them dispensed medications. The overall counseling approach was found to be $42.6 \%$ which improved to $58.3 \%$ when the pseudo-clients demanded it. Duration (73.3\%) and signs/ symptoms (45\%) of headache were asked before dispensing the medications. Dosing frequency (86.7\%), indication (60\%) and dosage form (35\%) were the most discussed items. Ibuprofen (45\%) and diclofenac (41.5\%) were primarily added to paracetamol for better headache treatment. Effectiveness (61.7\%) and cost (21.7\%) were the main criteria to choose drugs. In the cross-sectional survey, 60 participants were requested and 51 of them agreed to participate (response rate of $85 \%$ ). Of these participants, $64.7 \%$ agreed that managing headache symptomatically is challenging. Patient lack of confidence in dispensers (41.2\%) and lack of updated medical information (31.4\%) were reported as the primary barriers to counsel clients.

Conclusion: This study demonstrated the practical gaps in counseling practices and poor headache management of community pharmacies in Gondar city. National stakeholders in collaboration with academic organizations should be involved in continuous clinical training and education regarding proper counseling practices.
\end{abstract}

Keywords: Community medicine retail outlets, Counseling, Headache, Pseudo client, Ethiopia

\footnotetext{
* Correspondence: Kassieadeladlew21@gmail.com

'Department of Clinical Pharmacy, School of Pharmacy, College of Medicine

and Health Sciences, University of Gondar, P.O. Box: 196, Chechela Street,

Lideta Sub City Kebele 16, Gondar, Ethiopia

Full list of author information is available at the end of the article
}

(c) The Author(s). 2018 Open Access This article is distributed under the terms of the Creative Commons Attribution 4.0 International License (http://creativecommons.org/licenses/by/4.0/), which permits unrestricted use, distribution, and reproduction in any medium, provided you give appropriate credit to the original author(s) and the source, provide a link to the Creative Commons license, and indicate if changes were made. 


\section{Background}

Headache or cephalalgia affects infrequently almost everyone [1]. The Global Burden of Disease Study 2015 (GBD2015) ranked migraine as the third highest cause for disability worldwide in persons younger than 50 years in both sexes [2]. and nearly $40 \%$ of people suffered from a headache at some time in their lives [1]. Around 15\% of UK adult patients experience a migraine with a three-to-one ratio of women-to-men [1]. According to a population-based national survey of headache burdens in Ethiopia, the prevalence had been reported as migraine (17.7\%), tension-type headache (TTH) (20.6\%), probable medication-overuse headache $(\mathrm{pMOH})$, and headache yesterday $6.4 \%$ [3]. Patients most regularly seek professional counseling from general and neurologic clinics $[1,4]$. Headache challenges healthcare professionals in many ways and represents enormous social and economic burden to the health care system.; for example, 20 billion USD is lost every year in the United States for migraine $[1,2,5]$.

Community pharmacists are the most accessible healthcare professionals to the public owing to their convenient location at the heart of the community and wide geographic distribution [6]. Patients with a headache successfully self-medicate by means of over-the-counter (OTC) medications that are available via CMROs [7]. This provides a unique opportunity for pharmacy staffs to play a crucial role in ensuring the quality use of medications by providing patients with counseling on the safe, correct and effective use of medicines, and solving potential drug-related problems [8,9]. Even though CMROs can sufficiently treat minor ailments and contribute in self-care management such as headaches, still they need to be careful while recommending OTC drugs since even these drugs can cause health threats if used inappropriately [10]. Findings from developing countries showed that dispensers working in the pharmacies hardly keep sufficient knowledge and skills for effective syndrome management [11]. On the other hand, pharmacists in developed nations, such as the United Kingdom and Australia, successfully incorporated minor ailment management with other public-health programs [12-15]. In Ethiopia as in most developing countries pharmacy staff are largely confined to the traditional medication dispensing and counseling practices and once in a while delivering such public health services $[16,17]$ which is worsened by the absence of standard and consistence treatment (counseling) guidelines for headache and other common minor ailments [18]. Regarding self-medications and related issues, a variety of investigations were conducted in many parts of Ethiopia, though many of them used client perceptions $[19,20]$. Owing to the burden of headache in Ethiopia [3], patients usually look for immediate therapy in the nearby public pharmacies. A recent study conducted by Ayele et al. identified lack of access to clinical training and poor community awareness as the most commonly cited barriers for providing public health services in CMROs such as headache management [21]. Yet, the extent to which pharmacy professionals interacts with patients for headache management is not studied in detail, and there is no published data that explores pharmacy staff knowledge and counselling skills when it comes to handling patients' request of analgesic medications. Thus, the current study aimed at assessing the knowledge and extent of community pharmacy professionals' involvement in counseling practices and overall management of a headache as well as to explore the challenges and hidden reasons that hindered professionals from delivering the standard care to the clients.

\section{Methods \\ Study design and setting}

A dual-phase mixed-methods research design, including a simulated client method (April, 2018) and a cross-sectional study survey (May, 2018) were employed. The study was conducted in Gondar town, Northwest Ethiopia. The town has a population of approximately 206,987 [22] and 66 community medicine retail outlets (CMROs) (40 community pharmacies and 26 drug stores). This study was reviewed and ethically approved by the Institutional Review committee of the University of Gondar, School of Pharmacy with the approval number of (UOG-SOP204/2018). The data collected were kept anonymous and no personal identifier were used.

\section{The simulated patient (SP) study}

According to Food, Medicine and Healthcare Administration and Control Authority of Ethiopia (FMHACA), community medicine retail outlets (CMROs) are mainly classified into a pharmacy, drug store (shop) and drug vendor. Gondar town's CMROs were classified by geographical locations such as Arada, Piassa, Lideta (Chechela), Maraki and Azezo sub-cities (Kifle Ketemas) and all of the community medicine retail outlets were taken as study samples. Each of the CMROs was visited once by a pseudo-patient within study period giving a total of 60 (1 in each CMROs) pseudo-patient visits. Details of the scenario (an intermittent headache) employed in the simulated study are presented in Table 1 . The pharmacist was expected to rule out other medical conditions, medication history and advise the pseudo-client to take paracetamol combined with other analgesics such as nonsteroidal anti-inflammatory drugs (NSAIDS) or weak opioids like tramadol, and if inadequate and the symptom still persists advice to visit the nearby hospital or clinic. 
Table 1 The scenario employed in the simulated study, Gondar, 2018

Intermittent headache

The SP is a 20-year-old male with a complaint of an intermittent (moderate-to-severe) headache for 04 days duration. The SP is currently taking paracetamol to alleviate his symptom. Yet, he sensed that he needs a more effective treatment and, hence, visited a community pharmacy.

The pharmacist was given the The SP had no other previous or current following information when medical condition. The SP did not drink asked:
The headache started 04 days back and the SP had the symptom for most of the days.

The pain was described as mild, dull, low intensity, and affecting both sides of the head.

Paracetamol was the only medication the SP was taking during that time.

There were no special factors that trigger/worsen the headache.

The patient did not visit a hospital for this cause.

\section{The pseudo-client method}

Pseudo (simulated)-patient method is a technique of assessing the service providers' (dispensers') counseling practices in CMROs by visiting the pharmacy staff after training specific patient scenario. The aim of the pseudo-client-based study was to assess the participation of CMROs dispenser staffs in the management of a self-diagnosed headache and to explore the challenges and hidden reasons that impede the delivery of standard counseling services to the clients. This method has been employed extensively and comprehensively in pharmacy practice-based researches [23, 24].

Two clinical pharmacists acted as simulated patients. A half-day long discussion and training were given to the SPs so that they will be familiar and be able to perform the given clinical scenario. They were instructed not to give and/or ask further information unless asked by the pharmacy staff so as to make sure that the information provided by each SPs is uniform across all visits. In order to avoid dependence on the human cognitive processes, which has been mentioned as a potential limitation of the simulated patient method [25], all the visits were audio recorded. Immediately after each visit, the SPs filled the data gathered into a form containing a checklist of items (such as enquiries including: client history, information provided by dispensers, selfdiagnosis, medication selection process, direction for use and medical profile, aggravating and alleviating factors, and duration of headache) that were intended to assess the practice of pharmacy personnel toward the dispensing of antibiotics for the specified minor ailments. The principal investigator (AKN) compared and validated the data from the checklist against audio recordings for the purpose of quality assurance.

\section{The cross-sectional study}

A self-administered English version questionnaire was prepared and distributed to 63 community pharmacists (one in each CMRO) after securing verbal and written consent and clarification of the aim of the study. One of the working staffs of dispenser was selected randomly when there were two or more dispenser staffs during data collection. The questionnaire contains respondents' demographic factors, working hours, average client waiting time, dispensing experiences, headache management practices, and potential barriers to proper service delivery. Each questionnaire took an average of $15 \mathrm{~min}$. Finally, the completed questionnaire was collected on-site by the investigators.

\section{Data quality control, entry, analysis and interpretation}

The overall data was checked for its completeness and accuracy and important variables were addressed. Data from both the simulated and the cross-sectional studies were entered into and analyzed using Statistical Package for Social Studies (SPSS) version 20.0 [26]. The results were presented as frequencies and percentages.

\section{Operational definitions}

Community medicine retail outlets in our study as described in [27]:

\section{Pharmacy}

It denotes a drug shop having the mandate to hold any medicine and medical equipment. In addition, the professional who is supposed to dispense inside the pharmacy is 'A pharmacist'. No one else is allowed to dispense according to the FMHACA of Ethiopia.

\section{Drug store}

Unlike a pharmacy, a drug store is a drug shop but the medicine to be dispensed here is restricted. That means, it is not legal to hold every medication in this medicine retail outlet. For instance: It is not allowed to hold medications like psychotropic/narcotic drugs. In addition, the professional who is supposed to dispense inside the drug store is 'A druggist'.

\section{Pharmacists}

In Ethiopia, pharmacists are professionals having a bachelor degree from private or government university. In addition, they took all the courses that one medication expert has to know at the end. The duration of the study to be a pharmacist used to be four years which has been changed to five years since 2008 . 


\section{Druggists}

We can use this name interchangeably with' Pharmacy technician'. In Ethiopia, those professionals having 'diploma degree' from colleges are considered druggists (i.e. it is not a university-level education). They took courses for 3 years only and it is not that much comprehensive like pharmacists..

\section{Result}

\section{Pseudo client approach}

Out of the 66 CMROs, 60 of them were visited by the pseudo-patient approach whereas the rest were non-functional (closed) during the data collection. Among the evaluated respondents, the majority $(n=32$, $53.3 \%)$ were females. Thirty-four $(56.7 \%)$ of the premises were leveled as pharmacies. Almost all the participants dispensed medications for the pseudo-patient (95\%), while $3(5 \%)$ dispensers suggested the client to consult physicians to identify the cause of a headache. More than half of the participants provided information when the pseudo-client demanded it (58.3\%) and dispensed generic drugs (73.3\%); ibuprofen (45\%) and diclofenac (41.5\%) were the most recommended ones for a headache in addition to paracetamol. Effectiveness (61.7\%) and cost (21.7\%) were the major reasons to choose drugs for pseudo-clients as illustrated in Table 2.

Overall professional counseling approach of the dispensers was assessed by a five-point Likert scale (poor = 1 , fair $=2$, good $=3$, very good $=4$, and excellent $=5$ ). The mean $( \pm \mathrm{SD})$ counseling approach of dispensers was 2.14 (0.9) which means only $42.6 \%$ of dispensers gave proper counseling. During the pseudo-client approach, most dispensers asked primarily duration $(n=44,73.3 \%)$ and types of signs/symptoms $(n=27,45 \%)$ of a headache before dispensed the medications. Also, $48.3 \%$ of them allowed SP to be involved in the medication-selection process. Just below half (45\%) of the providers inquired signs or symptoms and around 22\% asked the SPs about the type of medication previously taken. Only 5 (8.3\%) dispensers asked whether they have previous or current medical condition whereas nearly $12 \%$ of them asked about their current medication profile other than paracetamol. Furthermore nobody asked about whether the pseudo-client needed additional information, the presence of allergic history, adverse drug reaction, and alleviating factors (Table 3 ).

Among the most commonly signposted information that every dispensary personnel should counsel every patient when dispensing pharmaceutical formulations, drug administration times (frequency) $(n=52,86.7 \%)$, medication indication $(n=36,60 \%)$ and dosage form $(n=21,35 \%)$ were the most discussed items during interaction with the simulated patients. To the contrary, none of the dispensers discussed important items such as contraindications, drug
Table 2 Drug selections and dispensing practices of CMROs in Gondar city during pseudo-client

\begin{tabular}{ll}
\hline Variables & $N(\%)$ \\
\hline Gender & $28(46.7)$ \\
Male & $32(53.3)$ \\
Female & \\
Community medicine retail outlets level & $34(56.7)$ \\
Pharmacy & $26(43.3)$ \\
Drug store & $57(95)$ \\
Dispensers who dispensed the drug for pseudo patient & $3(5)$ \\
Dispensers send SP to consult the doctor; not dispensed & \\
drugs & \\
Dispensed drugs product based on name & $44(73.3)$ \\
Generic & $13(21.7)$ \\
Brand & \\
Drugs were selected based on & $37(61.7)$ \\
Effectiveness & $13(21.7)$ \\
Cost & $7(11.7)$ \\
Both effectiveness and cost & 0 \\
ADR & $22(36.7)$ \\
Availability & $35(58.3)$ \\
Type of drug added to PCM for headache management & \\
Diclofenac & $25(41.7)$ \\
Ibuprofen & $27(45)$ \\
Tramadol & $3(5)$ \\
ASA & 0 \\
Acetaminophen with tramadol combined formulation & $2(3.3)$ \\
\hline Approach, 2018 (N=60) & \\
Provision of information for the pseudo client approach & \\
\hline
\end{tabular}

interactions, adverse drug reactions, adherence to treatment, and safe storage of the dispensed medications with the pseudo-clients (Fig. 1).

\section{Cross-sectional survey}

Among the 60 dispensers that were approached, 51 of them completed and returned (response rate of $85 \%$ ) the questionnaire. Almost two-thirds of the respondents were male $(62.7 \%)$ and ages between 22 and 30 years old (72.5\%). Of the CMROs, about $60 \%$ were leveled as pharmacies. A comparable number of pharmacists and druggists participated in the study. Average work experience as a dispenser in CMROLs was 5 years $( \pm \mathrm{SD}=2.9)$. The majority (62.7\%) of the dispensers reported to work for $8-10 \mathrm{~h}$ per day in the pharmacies with an average of $9.1( \pm 1.6)$ hours per day. Around $70 \%$ of participants reported that the average waiting time of clients in the dispensary was $5.2( \pm 2.34)$ minutes. Only one respondent 
Table 3 Questions and patient history's required by the provider during encounter

\begin{tabular}{lll}
\hline Items & \multicolumn{2}{l}{ Responses } \\
\cline { 2 - 3 } & Yes (\%) & No (\%) \\
\hline SPs age was asked during dispensing & $6(10)$ & $54(90)$ \\
$\begin{array}{l}\text { The provider let SP to be involved in the } \\
\text { medication-selection process }\end{array}$ & $29(48.3)$ & $28(46.7)$ \\
$\begin{array}{l}\text { The provider asked whether SP needed } \\
\text { additional information }\end{array}$ & 0 & $57(95)$ \\
$\begin{array}{l}\text { The provider personnel asked about the presence } \\
\text { of specific conditions that could affect diagnosis }\end{array}$ & $3(5)$ & $54(90)$ \\
$\begin{array}{l}\text { or recommended treatment } \\
\text { Starting time of headache }\end{array}$ & $13(21.7)$ & $44(73.3)$ \\
Location of pain & $1(1.7)$ & $56(93.3)$ \\
Magnitude (intensity) of pain & $4(6.7)$ & $53(88.3)$ \\
Duration of headache asked & $44(73.3)$ & $13(21.7)$ \\
Types of typical signs/symptoms of headache & $27(45)$ & $30(50)$ \\
asked & & \\
Current medication other than PCM asked & $7(11.7)$ & $50(83.3)$ \\
Previous or current medical condition asked & $5(8.3)$ & $52(86.7)$ \\
Type of medication history (Hx) previously & $13(21.7)$ & $44(73.3)$ \\
taken asked & & \\
Presence of allergy history asked & 0 & $57(95)$ \\
Major adverse reaction (ADRs) asked & 0 & $57(95)$ \\
Exacerbating factors & $2(3.3)$ & $55(91.7)$ \\
Relieving factors & 0 & $57(95)$ \\
\hline
\end{tabular}

had a guideline for headache management and $11.8 \%$ of the dispensers took clinical training in their work life. Detail socio-demographic characteristics are illustrated in Table 4.

According to the survey, most of the participants (64.7\%) agreed or strongly agreed that managing headache symptomatically is challenging. However, many of them agreed or strongly agreed to the importance of syndrome-approach clinical training (52.9\%) and continuous education and training (94.1\%) to solve such challenges. In addition, a higher number of respondents (54.9\%) agreed or strongly agreed that clients should involve in medication selection process (Table 5).

As to the respondents' reports, only one-third (33.3\%) of the clients had very good or excellent awareness with the dispenser's role inregard to seeking additional information beyond what they have already obtained, and one-fourth $(25.5 \%)$ were aware of generic and brand products (Table 6). The majority (66.7\%) of dispensers reported that clients preferred brand products while other clients considered effectiveness $(n=17,33.3 \%)$ and both price and effectiveness $(n=15,29.4 \%)$ for choosing the medications. High proportions (78.4\%) of community pharmacists and druggists recommended paracetamol for a non-examined headache, whereas, $60.8 \%$ of dispensers referred clients (who are taking paracetamol and in need of better treatment) to hospital or clinic. Less number of respondents recommended diclofenac (17.6\%) and tramadol (13.7\%). Lack of client interest towards professional counseling (41.2\%) and lack of updated medical information provided by dispensers (31.4\%) were the main potential barriers to counsel clients (Table 7).

\section{Discussion}

The present study evaluated the counseling manners and headache management practices of CMROs dispensers without a prescription in Gondar city. Essential variations concerning information provision and headache management practices of dispensers were discovered by comparing results found from the pseudo-client visits and the cross-sectional survey. Based on the SPs findings, the overall counseling approach was found to be $42.6 \%$; however, it was improved to $58.3 \%$ when the pseudo-client demanded it. In the same way, findings in

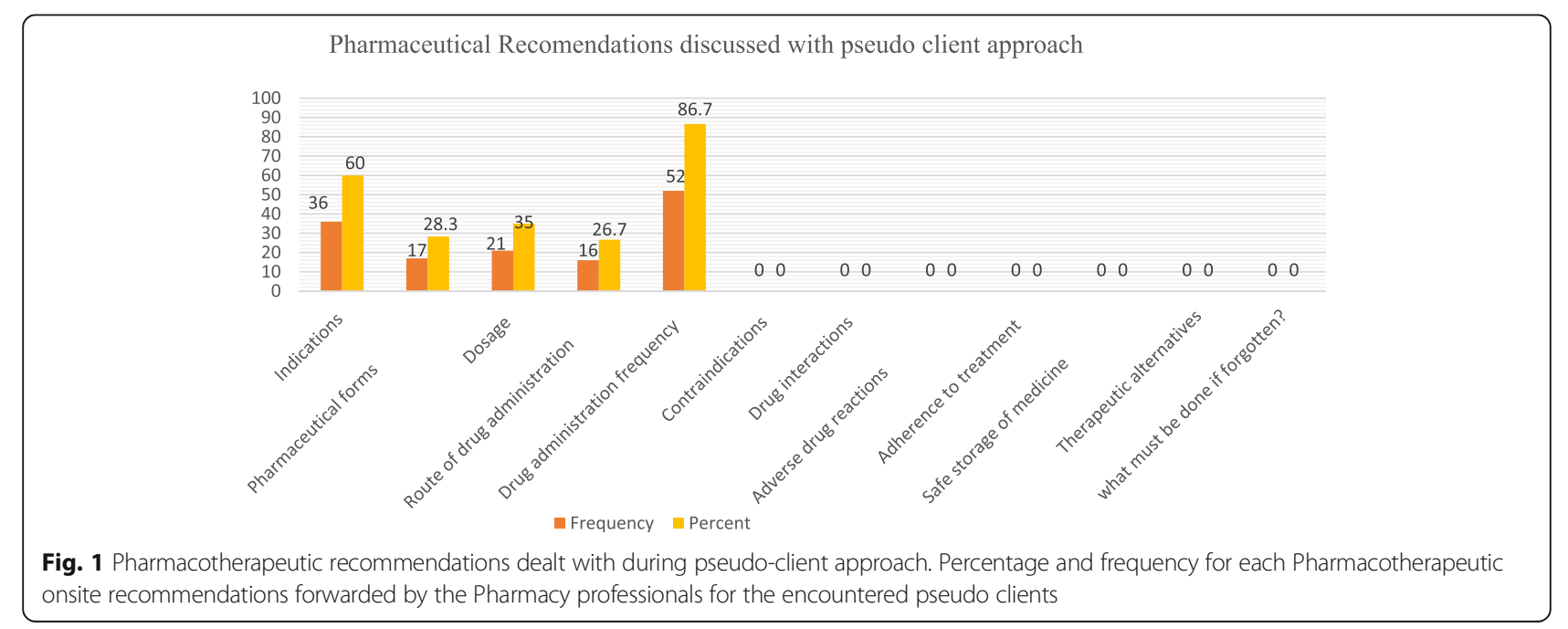


Table 4 Socio-demographic characteristics of participants, $(N=51)$

\begin{tabular}{|c|c|c|}
\hline Characteristics & $N(\%)$ & Mean $( \pm \mathrm{SD})$ \\
\hline \multicolumn{3}{|l|}{$\overline{\text { Sex }}$} \\
\hline Male & $32(62.7)$ & \\
\hline Female & 19 (37.3) & \\
\hline \multicolumn{3}{|l|}{ Age in years } \\
\hline $22-30$ & $37(72.5)$ & $29.7( \pm 4.1)$ \\
\hline $31-40$ & $13(25.5)$ & \\
\hline$>40$ & $1(2)$ & \\
\hline \multicolumn{3}{|c|}{ Work experience in (years) } \\
\hline$<1$ years & $2(3.9)$ & $5( \pm 2.9)$ \\
\hline $1-5$ years & $32(62.7)$ & \\
\hline$>5$ years & $17(33.3)$ & \\
\hline \multicolumn{3}{|c|}{ Length of working time (in hours) } \\
\hline $1-8 \mathrm{~h}$ & 19 (37.3) & $9.1( \pm 1.6)$ \\
\hline $8-10 h$ & $32(62.7)$ & \\
\hline \multicolumn{3}{|c|}{ Average client waiting time (in minutes) } \\
\hline $1-5 \min$ & $35(68.6)$ & $5.2( \pm 2.34)$ \\
\hline $6-10 \mathrm{~min}$ & $16(31.4)$ & \\
\hline \multicolumn{3}{|c|}{ Educational qualification } \\
\hline Pharmacist & $26(51)$ & \\
\hline Druggist & $25(49)$ & \\
\hline \multicolumn{3}{|c|}{ Level of drug retail outlet } \\
\hline Pharmacy & $27(52.9)$ & \\
\hline Drug store & $24(47.1)$ & \\
\hline \multicolumn{3}{|c|}{ Dispensers who had guideline for headache management } \\
\hline Yes & $1(2)$ & \\
\hline No & $50(98)$ & \\
\hline \multicolumn{3}{|c|}{ Dispensers took clinical training in their work life } \\
\hline Yes & $6(11.8)$ & \\
\hline No & $45(88.2)$ & \\
\hline
\end{tabular}

Riyadh, Saudi Arabia showed that the counseling level was found to be $43 \%$ even though it was enhanced when SPs demanded more information [28]. Depending on the type of investigation methodologies, the stated advising levels fluctuated from 8 to $100 \%$ in the worldwide literature [29]. Based on this, the reasons for such poor counseling practices might be multifactorial. The main challenges include lack of interest, poor experiences, knowledge and communication skills, and lack of standard counseling guideline.

In the real dispensing practices, $95 \%$ of dispensers provided medications for the pseudo-customers who were taking paracetamol while three dispensers advised the client to consult the physicians for identifying the cause of a headache without any further professional trail to help. This study is quite comparable with the study done in Saudi Arabia [28]. Contrarily, in the cross-sectional survey, $60.8 \%$ of participants referred the client to the hospital. This indicates that community pharmacists were not dispensing drugs based on knowledge and guidelines rather they sold for only cheesing money. Since most of CMROs are established for profit, no matter what the cause is, they sell every product without any hesitations. Moreover, unless they are profitable, their survival will be jeopardized and mainly unserved customers might disclose them to others clients that they do not serve well.

Concerning headache management using OTC medications, analgesics such as non-steroidal anti-inflammatory drugs (NSAIDs), acetaminophen, and weak opioids like tramadol are suggested as first-line drugs. Nevertheless, $64.7 \%$ of participants in the cross-sectional survey agreed that managing headache symptomatically is challenging, $78.4 \%$ of dispensers recommended acetaminophen for a non-examined headache, and about $40 \%$ of them added diclofenac, tramadol, and ibuprofen to paracetamol for better treatment. On the other hand, in the SPs approach, 95\% of the participants primarily added Ibuprofen (45\%), diclofenac $(41.5 \%)$ and tramadol (5\%) to acetaminophen for a headache management, though dispensers reported that customers chose brand products in the survey. Higher proportions of the dispensers selected the medications based on their effectiveness (61.7\%) and cost (21.7\%) which had similarities with survey results. In contrast, a pilot study in Brazil reported sodium dipyrone was the most recommended medication [30]. Even though customers do want brand products, suppliers rarely made them available for the community so that acetaminophen, ibuprofen, and diclofenac would be the first choice, since these drugs are safe, effective, readily available and affordable for most of the local customers.

During the pseudo-client approach, headache duration and signs or symptoms, medication profile and previous or current medical conditions were inquired by the dispensers. It is very important that dispensers pursue relevant evidence about clients' history and compliant characteristic which enables them to choose appropriate pharmacotherapeutic alternatives for customers. However, forwarding many questions towards clients requires strong communication skills and knowledge, and increases client confidence and counseling satisfaction on dispensers. Such types of questions are highly supported by many comparative findings [31, 32].

Though higher proportions of participants (54.9\%) in the cross-sectional survey agreed with the clients' involvement of medication selection, smaller number of dispensers practically allowed the pseudo-client to be involved with their medication selection process. Surprisingly, nobody asked about whether the pseudo-client needed additional information, the presence of allergic 
Table 5 Belief of dispensers on headache management challenges and solutions

\begin{tabular}{|c|c|c|c|c|}
\hline Items & Number & Strongly disagree/Disagree (\%) & Neutral (\%) & Agree/strongly agree (\%) \\
\hline Managing headache symptomatically is challenging & 51 & $9(17.7)$ & $9(17.6)$ & $33(64.7)$ \\
\hline $\begin{array}{l}\text { Syndrome approach clinical training is important } \\
\text { for treating headache }\end{array}$ & 51 & $11(21.5)$ & $13(25.5)$ & $27(52.9)$ \\
\hline $\begin{array}{l}\text { Continuous education and training improves challenges } \\
\text { to treat headache }\end{array}$ & 51 & 0 & $2(3.9)$ & $49(94.1)$ \\
\hline Patients should be involved in drug selection process & 51 & $14(27.4)$ & $9(17.6)$ & $28(54.9)$ \\
\hline
\end{tabular}

history, adverse drug reaction history, and alleviating factors of a headache. Since self-medications are retailed without any prescription dispensers thought that many questions might discourage the patients form taking the medications [33]. Furthermore, in order to provide additional information and understand typical allergic history and adverse drug reactions providers should be trained for such types of evidence and clients' interest. The survey revealed that clients' absence of interest on dispensers and lack of updated medication information were found to be the major challenges for better counseling. However, 95\% of respondents reported that the community was award of the role of community pharmacists in headache management.

When dispensing pharmaceutical formulations, there are important points that every dispenser should acknowledge and counsel the clients during providing drugs. However, the findings of this study revealed that only a few of the dispensers informed the clients about drug administration times (frequency), medication indication, dosage (strength), pharmaceutical forms, and route of drug administration during interaction with the simulated patients. To the contrary, none of the dispensers discussed important items such as contraindications, drug interactions, adverse drug reactions, adherence to treatment, and safe storage of the dispensed medications with the pseudo client. The findings of this study were similar to previous studies with regard to the rare provision of essential information by community pharmacists on precautions, adverse effects, drug interactions, contraindications, and safe storage $[23,24,34]$. But a Saudi study reported somewhat different results where $97 \%$ of the SPs visits provided information about dose, whereas a very small number of SPs were counseled on precaution. To the contrary, about half of the respondents never counseled on the side effects and drug interactions [28]. As explained earlier most of the provided counseling was superficial, easy and common that any health professionals might provide for every client. Mainly dispensers merely focus particularly on sales rather than counseling, because detailed discussions need further professional skills and extensive knowledge to deliver. Moreover, most of the patients do not seek more detailed information. Rather they need only what they want to know.

\section{Strength and limitations of the study}

Every pseudo-client visit was audio-recorded to reduce the challenges associated with the human cognitive processes in conducting SP studies. After all, this study showed the real gap between the practical services and the theoretical expectations of community pharmacies. However, we used a convenience sampling method in only Gondar city. Therefore, generalizations of the study findings to other regions and populations should be with caution as it might lead to under or over representations. In addition, because only a specific case scenario was employed that leads to specific replies, it may not comprehensively assess the professionals' competency towards a headache management. Moreover, because of the pseudoclient visit and the cross-sectional survey was conducted at different times, the respondents might not be the same and the responses to the self-administered questionnaire depended on the respondents' trustworthiness which is subjected to socially desirable responses.

\section{Conclusions}

Community pharmacists, being one of the most easily accessible health professionals in the community, are uniquely positioned to treat and manage minor ailments such as headache in their practice areas. According to findings from this study, community pharmacies demonstrated a very poor and inadequate skill headache management.

Table 6 Community awareness's and approaches towards CMROs

\begin{tabular}{lllll}
\hline Items & Number & Poor/ fair (\%) & Good (\%) & Very good/ excellent (\%) \\
\hline $\begin{array}{l}\text { Community awareness towards the role of community medicine } \\
\text { retail outlets in headache management }\end{array}$ & 51 & $5(9.8)$ & $29(56.9)$ & $17(33.3)$ \\
$\begin{array}{l}\text { Patients' interest to get additional information beyond you provide } \\
\text { Communities awareness of generic and brand name of drugs }\end{array}$ & 51 & $20(39.2)$ & $14(27.5)$ & $17(33.3)$ \\
\hline
\end{tabular}


Table 7 Dispensers and clients drug selection and counseling barriers

\begin{tabular}{ll}
\hline Items & $N(\%)$ \\
\hline $\begin{array}{l}\text { Type of product preferred by clients } \\
\text { Generic }\end{array}$ & $17(33.3)$ \\
Brand & $34(66.7)$ \\
What do client matters to choose their medication & \\
Price & $5(9.8)$ \\
Effectiveness & $17(33.3)$ \\
Price and effectiveness & $15(29.4)$ \\
Effectiveness and safety & $10(19.6)$ \\
Price, effectiveness and safety & $4(7.8)$ \\
Drugs recommended for non-examined headache & \\
Paracetamol & $40(78.4)$ \\
Diclofenac & $5(9.8)$ \\
Ibuprofen & $3(5.9)$ \\
Tramadol & $3(5.9)$ \\
Aspirin (ASA) & 0
\end{tabular}

What would you do for a headache patient taking paracetamol who wanted better treatment

$\begin{array}{ll}\text { Diclofenac } & 9(17.6) \\ \text { Ibuprofen } & 4(7.8) \\ \text { Tramadol } & 7(13.7) \\ \text { Refer to nearby hospital } & 31(60.8) \\ \text { Aspirin (ASA) } & 0 \\ \text { Potential barriers to counsel the clients } & \\ \text { High patient load } & 6(11.8) \\ \text { Shortage of time } & 3(5.9) \\ \text { Lack of un updated information } & 16(31.4) \\ \text { Patients lack of awareness to be counseled } & 5(9.8) \\ \text { Patient lack of interest } & 21(41.2)\end{array}$

Providing continuous clinical training and educational interventions are needed in order to mitigate the knowledge and skill gap. One suggestion is providing a hands-on evidence-based summary of headache management in their practice areas by academic institution and other stakeholders. Large scale studies that can explore community pharmacists' involvement in managing headache in community pharmacies and that further could assess clients' (purchasers') level of satisfaction towards the community pharmacy service particularly regarding headache management is recommended to identify practice barriers and to better inform regulatory bodies.

\section{Abbreviations}

ADR: Adverse Drug reaction; CMROs: Community medicine retail outlets; FMHACA: Food, Medicine, Healthcare Administration and Control Authority; GBD: Global Burden of Disease; Hx: History; $\mathrm{MOH}$ : Ministry of health; NSAIDs: Nonsteroidal anti-inflammatory drugs; OTC: Over the counter;
PCM: Paracetamol; PCs: Pseudo clients; SD: Standard Deviation; SPS: Simulated patients; SPSS: Statistical Package of Social Sciences; TTH: Tension type headache; UK: United Kingdom; USD: United States Dollar

\section{Acknowledgements}

We would like to thank the study participants for their valuable information and time.

\section{Availability of data and materials}

All relevant materials and data supporting the findings of this study are contained within the manuscript and the datasets used and/or analyzed during the current study are available from the corresponding author on reasonable request.

\section{Authors' contributions}

AKN and SAB contributed in conceptualization, project administration, formal analysis, investigation, methodology, supervision, data curation, resources, writing and original draft of the manuscript and writing, review and editing of the final manuscript. DAE, AKS, EAG, NYM and AKN contributed in formal analysis, methodology, data curation, writing and original draft of the manuscript. All authors of this manuscript read and approved the final version of this manuscript.

\section{Ethics approval and consent to participate}

This study was reviewed and ethically approved by the Institutional Review committee of University of Gondar, School of Pharmacy with the approval number of SOP204/2018. The data collected was kept anonymous and recorded in such a way that the identity of the involved pharmacy professionals could not be known. The exit interviews were conducted where a third-party could not overhear questions and answers so as to ensure privacy and confidentiality of clients. The information obtained from the study was not disclosed to the third body. Only coded numbers were used to identify study participants.

\section{Consent for publication}

Not applicable.

\section{Competing interests}

The authors declare that there is no competing interest.

\section{Publisher's Note}

Springer Nature remains neutral with regard to jurisdictional claims in published maps and institutional affiliations.

\section{Author details}

'Department of Clinical Pharmacy, School of Pharmacy, College of Medicine and Health Sciences, University of Gondar, P.O. Box: 196, Chechela Street, Lideta Sub City Kebele 16, Gondar, Ethiopia. ${ }^{2}$ Department of Psychiatry, University of Gondar, Chechela Street, Lideta Sub City Kebele 16, Gondar, Ethiopia.

Received: 5 September 2018 Accepted: 5 October 2018

Published online: 16 October 2018

\section{References}

1. Steiner TJ, Macgregor EA, Davies PTG (2007) Guidelines for all healthcare professionals in the diagnosis and management of migraine, tension-type, cluster and medication-overuse headache, 3rd edn (1st revision). British Association for the Study of Headache

2. International Headache Society (IHS) (2018) The International Classification of Headache Disorders (ICHD-III). 3rd edition. Cephalalgia 38(1):1-211

3. Zebenigus M, Tekle-Haimanot R, Dawit K, Worku DK et al (2017) The burden of headache disorders in Ethiopia: national estimates from a populationbased door-to-door survey. J Headache Pain 18:58. https://doi.org/10.1186/ s10194-017-0765-7

4. Steiner TJ, Scher Al, Stewart WF, Kolodner K, Liberman J, Lipton RB (2003) The prevalence and disability burden of adult migraine in England and their relationships to age, gender and ethnicity. Cephalalgia 23:519-527

5. Gahir KK, Larner AJ (2004) What role do community pharmacists currently play in the management of headache? A hospital based perspective. Int J Clin Pract 58(3):257-259 
6. Chua SS et al (2006) Response of community pharmacists to the presentation of back pain: a simulated patient study. Int J Pharm Pract 14:171-178

7. Steiner TJ, Lange R, Voelker M (2003) Aspirin in episodic tension-type headache: placebo controlled dose-ranging comparison with paracetamol. Cephalalgia 23:59-66

8. Berger $\mathrm{K}$ et al (2005) Counselling quality in community pharmacies: implementation of the pseudo customer methodology in Germany. J Clin Pharm Ther 30:45-57

9. Schneider CR et al (2009) Measuring the assessment and counseling provided with the supply of nonprescription asthma reliever medication: a simulated patient study. Ann Pharmacother 43:1512-1518

10. Alonzo HGA, Cristiana L, Corrêa CL, FAD Z (2001) Analgesics, antipyretics and non-steroidal anti-inflammatory drugs: epidemiological data on six intoxication control centers in Brazil. Rev Bras Toxicol 14:49-54

11. Hussain A, Ibrahim M (2012) Management of diarrhoea cases by community pharmacies in 3 cities of Pakistan. East Mediterr Health J 18(6):635-640

12. Sewak NP, Cairns J (2011) A modeling analysis of the cost of a national minor ailments scheme in community pharmacies in England. IJPP 19(s1):50

13. United-Kingdom Department of Health (2005) Choosing health through pharmacy-a programme for pharmaceutical public health 2005-2015

14. Pharmaceutical Service Negotiating committee (2005) NHS community pharmacy contractual framework enhanced service: minor ailment service, pp 9-11

15. Benrimoj S, Frommer M (2004) Community Pharmacy in Australia. Aust Health Rev 28(2):238-246

16. Surur AS, Getachew E, Teressa E, Hailemeskel B, Getaw NS, Erku DA (2017) Self-reported and actual involvement of community pharmacists in patient counseling: a cross-sectional and simulated patient study in Gondar, Ethiopia. Pharm Pract 15(1):890. https://doi.org/10.18549/PharmPract.2017. 01.890 PMID: 28503225

17. Erku DA, Mekuria AB, Surur AS, Gebresillassie BM (2016) Extent of dispensing prescription-only medications without a prescription in community drug retail outlets in Addis Ababa, Ethiopia: a simulated-patient study. Drug Healthc Patient Saf 8:65-70

18. Sumia S, Mohamed A, Mahmoud AA (2014) The role of Sudanese community pharmacists in patients' self-care. Int J Clin Pharm 36:412-419. https://doi.org/10.1007/s11096-013-9911-8 PMID: 24442644

19. Ayalew MB (2017) Self-medication practice in Ethiopia: a systematic review. Patient Prefer Adherence 11:401-413. https://doi.org/10.2147/PPA.S131496 PMID: 28280312

20. Hailemichael W, Sisay M, Mengistu G (2016) Assessment of the knowledge, attitude, and practice of self-medication among Harar health sciences college students, Harar, eastern Ethiopia. J Drug Deliv Ther 6:31-36

21. Ayele AA, Mekuria AB, Tegegn HG, Gebresillassie BM, Mekonnen AB, Erku DA (2018) Management of minor ailments in a community pharmacy setting: findings from simulated visits and qualitative study in Gondar town, Ethiopia. PLoS One 13(1):e0190583. https://doi.org/10.1371/journal.pone.0190583

22. Complete report on 2007 Ethiopian census. Central statistical agency. http:// www.csa.gov.et/census-report/complete-report/census-2007. Accessed 28 Jul 2018

23. Gokcekus L, Toklu HZ, Demirdamar R, Gumusel B (2012) Dispensing practice in the community pharmacies in the Turkish republic of northern Cyprus. Int J Clin Pharm 34(2):312-324

24. Bin Abdulhak A, Al Tannir M, Almansor M et al (2011) Non prescribed sale of antibiotics in Riyadh, Saudi Arabia: a cross sectional study. BMC Public Health 11(1):538

25. Werner JB, Benrimoj SI (2008) Audio taping simulated patient encounters in community pharmacy to enhance the reliability of assessments. Am J Pharm Educ 72:136 PMID: 19325956

26. IBM Corp (2012) IBM SPSS statistics for windows, version 21.0. IBM Corp. Released, Armonk

27. Belachew SA, Tilahun F, Ketsela T, Achaw Ayele A, Kassie Netere A, Getnet Mersha A et al (2017) Competence in metered dose inhaler technique among community pharmacy professionals in Gondar town, Northwest Ethiopia: knowledge and skill gap analysis. PLoS One 12(11):e0188360. https://doi.org/10.1371/journalpone.0188360

28. Alaqeel S, Abanmy NO (2015) Counselling practices in community pharmacies in Riyadh, Saudi Arabia: a cross-sectional study. BMC Health Serv Res 15:557. https://doi.org/10.1186/s12913-015-1220-6

29. Puspitasari HP, Aslani P, Krass I (2009) A review of counseling practice on prescription medicines in community pharmacies. Res Soc Adm Pharm 5: 197-210
30. Santos AP, Mesquita AR, Oliveira KS, Lyra DP Jr (2013) Assessment of community pharmacists' counselling skills on headache management by using the simulated patient approach: a pilot study. Pharm Pract 11(1):3-7

31. Smiley $T$. The role of the pharmacist in identification, referral, and management of migraine headache. CE Compliance Centre National Continuing Education Program December 2005

32. Berger K, Eickhoff C, Schulz M (2005) Counselling quality in community pharmacies: implementation of the pseudo customer methodology in Germany. J Clin Pharm Ther 30(1):45-57

33. Nair K, Dolovich L, Cassels A, McCormack J, Levine M, Gray J et al (2002) Whatpatients want to know about their medications: focus group study of patient and clinician perspectives. Can Fam Physician 48:104-110

34. Al-Mohamadi A, Badr A, Bin Mahfouz L, Samargandi D (2013) Dispensing medications without prescription at Saudi community pharmacy: extent and perception. Saudi Pharm J 21(1):13-18

\section{Ready to submit your research? Choose BMC and benefit from:}

- fast, convenient online submission

- thorough peer review by experienced researchers in your field

- rapid publication on acceptance

- support for research data, including large and complex data types

- gold Open Access which fosters wider collaboration and increased citations

- maximum visibility for your research: over $100 \mathrm{M}$ website views per year

At BMC, research is always in progress.

Learn more biomedcentral.com/submissions 